\title{
MACONDO Y COMALA, DOS FORMAS DEL INFIERNO EN LA NARRATIVA LATINOAMERICANA**
}

\author{
“(...) descendit ad inferos; \\ tertia die resurrexit a mortuis (...)" \\ Ordinariurn divini offlcii. \\ (...) descendió a los intiernos; \\ al tercer día resucitó de \\ entre los muertos (...." \\ Ordinario del Oficio Divino.
}

Las palabras que sirven de epígrafe a esta sencilla disertación, que no quiere ni puede ser erudita ni quiere ni puede as umir el talante de un enjundioso estudio crítico, puesto que soy apenas un hacedor de poemas que ejerce de maestro de escuela en mi país, han sido tomadas de la parte estival del Oficio Divino, según el antiguo rito tridentino, y nie vienen como anillo al ded3 para entrar con us tedes a ese hemoso y vasto inundo del infiemo, al que han bajado también Ulises y Eneas, Teseo, Hércules y Orfeo, Jesucris to y Dante, la estirpe de los Buendía y Juan Preciado.

De otra parte, no deja de somrenderme que en la puerta de entrada de ese lugar en el cual confluyen todas las carencias humanas, entre ellas, nuestra esencial incapacidad para comunicarnos, encontremos ins crito el verbo latino fero, diablo de palabra, trasgo o duende que se transfigura bajo la apariencia de otros nombres, y que significa llevar y traer, pres entar y obtener, sufrir y relatar; término fantasma y, por ello mismo, poético, que funda una dinastía de signos que dicen lo inefable como, por ejemplo, feraz, fortuna y azar; ablación, lucifer y preferencia; conferir, circunferencia; elación y preferir; superlativo, diferencia; ofrecer y transferir; de donde inferimos que por ese rumbo no podremos salir nunca del infierno -del Inferus-, el mundo de abajo, inferior y subterráneo.

\footnotetext{
* Profesor. Departamento de Lenguas. Universidad Pedagógica Nacional.

** Conferen cia leída por Angel Marcel en la Universidad Federal de Río de Janeiro el 9 de junio de 1995. y en la Asociación de Represent antes Culturales Iberoam ericanos, en Brasilia. el 14 del mismo mes.
} 


\section{Los infiernos poéticos, metáforas del mal}

Cuando ejerce el Oficio divino de la poesía, al poeta no le cabe la denominación de ser extraordinario, sino simplemente la de hombre en estado de alerta, en estado de emergencia permanente, que contempla el mundo para reflejarlo y reflejarse en él.

Ya Aldo Pellegrini ${ }^{1}$ en el bello libro que titula Para contribuir a la confusión general, nos advierte que en el acto de percibir la realidad para otorgarle sentido poético, el poeta se proyecta fuera de sí mismo, se despersonaliza, deja a un lado su ego para acudir al llamado de las cosas, de modo que pueda poseerlas. La de la poesía es, pues, una percepción activa, mucho más real y más completa que la que se logra con el anteojo del saber científico, pues lo que es objeto de aprehensión poética no está a flor de mundo sino en el fondo profundo de la tierra. El poeta sabe que, allende la superficie, subyace otra realidad más perdurable y más rica que, al trascender el tiempo y el es pacio, se universaliza, de manera que puede hacerse vigente para los hombres de las diferentes épocas y lugares.

Ese abandono del yo, ese ceder el ego en favor del mundo, no es otra cosa que un acto de amor en la opinión del ya citado Pellegrini y de muchas otras personas. Por eso, ama el que vive en el fondo de las cosas, y el amante entrega su ser, es decir, muere para conocer al ser amado y ser conocido por él.

Ello explica -y quizá no exista otra razón más sólida- que el saber poético sea válido y permanente desde Homero hasta nuestros días, y que no opere en él el criterio de "progreso" que gobierna las ciencias; lo que no implica inmovilismo por parte del poeta, sino simplemente que él se ocupa de lo que no pierde vigencia en e] seno de las transformaciones del mundo, del hombre y de la vida.

De otro lado, el saber poético emprende el camino de la sensibilidad intuitiva, que no del discurso racional. En este orden de ideas, "Novalis afimaba que la poesía es la infancia de las ciencias, y en efecto, el conocer poético es tá vinculado con el conocer mágico del niño, y participa de esa misma materia adivinatoria que establece sus primeros contactos con la realidad, y sin la cual no sería posible ningún conocimiento racional posterior".

No olvidemos que, en este sentido, poeta y profeta son la misma persona, y que el vate es el que vaticina, no porque sea dueño de poderes sobrenaturales, sino porque, a diferencia del hombre vulgar tiene el privilegio de conocer mejor la realidad y, por tanto, puede predecirla.

\footnotetext{
${ }^{1}$ PELLEGRINI, Aldo. "La universalidad de lo poético" en: Para contribuir a la confusión general. Nueva Visión, 1965, p. 36.

${ }^{2}$ Novalis, citado por Aldo Pellegrini. Ibid., págs. 37 y 38. 
Nada de extraño tiene, pues, que vates y poetas, y brujos y profetas vean mejor en la noche como los gatos, y que el sueño les revele de modo misterioso los secretos resortes de la realidad, sin los cuales no sería posible la identidad del soñador con lo soñado. Cierto. En la oscuridad, abandonadas por la luzque ciega, las cosas son ellas mismas, y el poeta, el iluminado, no hace otra cosa que alumbrar y traducir a su lenguaje personal los universos que ha vislumbrado, no importa que se llamen infierno o paraíso. De este modo, la poesía que es reflejo del mundo en el hombre y de éste en aquél, se confunde con la vida misma. Y una de las cosas que el universo ofrece para contemplar es la realidad del hombre de siempre y de todas partes; de donde inferimos -pues to que al infiemo vamos- que ningún conocimiento poético puede desconocer el ser del hombre. ¿Y qué cosa más humana para aprehender que la realidad esencial de sus carencias'?

Si dos se quieren bien, que no se nieguen

el hambre ni la sed ni la carencia;

que no pierdan el nombre con la confluencia

los que hacia el mar, fluviales, se congreguen.

Si dos se quieren bien, que no se entreguen

ni el beso mutuo calme la apetencia;

si hacen viaje común, a diferencia

de los que mal llegaron, nunca lleguen.

Sólo se busca el agua cuando es alta y ancha y honda la sed, y la reclama el que, viajero, esperas y no viene.

Yel hambre es más completa si nos falta la plenitud del mundo en plena rama; sólo se ama el amor que no se tiene ${ }^{3}$

Si la vida fuera plena y se nos apareciera el mundo como llenura, nada habría qué decir. Ello explica, por ejemplo, que las mal llamadas sociedades primitivas, mejor unidas que las nuestras a Natura y, por eso mismo, menos depredadoras que nosotros, no tuvieran que celebrar el día intemacional de la ecología. Me imagino que en Nigeria -país de negros- no tendría ningún sentido hablar de negritudes ni exaltar los valores de la raza, al menos que por alguna razón se sintieran discriminados. ¿Qué inferencia podemos sacar entonces de la celebración del día internacional de la mujer, del día de la paz, del amor y la amistad, sino que percibimos como carencias esas realidades y valores que tanto celebramos? Me atrevo a pensar que la expresión poética de esas faltas y vacíos, en boca de videntes y poetas y brujos y vates y profetas, corresponde a lo que las culturas invocan con el hombre genérico de mal, y que asume, según la lente con que se mire, la apariencia fantasmal de otras palabras: pecado aborigen para la religión judeo-cristiana; crimen y delito para la sociedad civil, regida por las leyes y

\footnotetext{
${ }^{3}$ Angel, Marcel. Transgresión y anacronismo. Bogotá: Gimnasio Moderno. 1990. p. 83.
} 
el derecho; enfermedad, desamor, injus ticia y soledad en la república universal de todo ser humano; maleficio en la visión del brujo. Y el lugar de encuentro, la confluencia de todos esos males, no puede ser otro que el infiemo, denominado también, según el Diccionario de sinónimos y antónimos, de Sainz de Robles ${ }^{4}$ como el abismo o el averno; el arco o el tártaro; antenora o báratro; gehena, fuego eterno, tinieblas exteriores, calderas de Pedro Botero, perdición, condenación eterna.

\section{Ulises baja al Reino de Hades}

Oigam os cómo relata Ulis es su viaje al Hades:

(...) Después de haber rogado con votos y suplicas a las generaciones de los muertos, tomé las reses, las desollé encima del hoyo, corrió la negra sangre, y al instante se congregaron, saliendo del Erebo, las almas de los difuntos: mujeres jóvenes, mancebos, ancianos que en otro tiempo padecieron males innumerables, tiernas doncellas con el ánimo angustiado por reciente pesar, y muchos varones que habían muerto en la guerra, heridos por broncíneas lanzas y que mostraban aún ensangrentadas amaduras. Agitábanse todas con grandísimo clamoreo alrededor del hoyo, unas por un lado y otras por otro: $\mathrm{y}$, al verlas, señoreose de mi el pálido terror. En seguida exhorté a los compañeros y les di orden de que desollaran las reses, tomándolas del suelo donde yacían degolladas por el cruel bronce, y las quemaran inmediatamente, haciendo votos al poderoso Hades y a la venerable Perséfone; y yo, desenvainando la aguda espada que llevaba junio al muslo, me senté y no permití que las vanas cabezas de los muertos se acercaran a la sangre antes de haber interrogado a Tiresias. $(. .)^{5}$.

Notables helenistas y críticos literarios, entre los cuales no me cuento, han hablado con sapiencia y donosura del sentido que puede tener el descenso de Ulises a los infiernos, y el haber escuchado de los muertos la misma historia humana que hoy podemos oír de labios de quienes a duras penas sobreviven.

Por su difunta madre, Ulises se enteró de la condición de los mortales cuando fenecen, “(...) para que luego -según dijo-, una vez en tu palacio, puedas referirlas a tu consorte" . Por boca de Tiro, hija del insigne Salmoneo y esposa de Creteo Eólida, supo que Poseidón se acostó con ella y la poseyó, haciéndose pasar por Enipeo. Y Agamenón Atrida le contó cómo, con la complicidad de su traidora esposa, Egis to lo invitó a su casa, le dio de comer y le quitó la vida como se mata según dijo- al buey junto al pesebre. La historia de siempre y de cualquier parte. No se extrañen pues, señoras y señores, si un día de es tos o a la salida misma de

\footnotetext{
${ }^{4}$ SAINZ DE ROBLES, Federico Carlos. Ensayo de un diccionario español de sinónimos y antónimos. Madrid: Aguilar, 1973. pp. 624 y 625.

${ }^{5}$ HOMERO. La odisea. Obras maestras. Barcelona: Iberia. 1952, p. 138.

${ }^{6}$ Ibid., p. 138.
} 
esta conferencia, se encuentran con Ulises, como yo me topé con él en algún aeropuerto, mientras hacía viaje de regreso a mi país.

Vuelve Ulises de Pérgamo. Las penas

le dan nombre y el odio lo apellida.

¿Qué fue de llión, del sitio y la caída

y del llanto de amor de las sirenas?

Ha llegado de Ogigia a las ajenas

patrias que a nadie dan la bienvenida;

él espera en el muelle la salida

para Corintos, Itaca o Atenas.

Si de Ilión se va a Thiaki por Esparta, ¿Cómo ha llegado entonces hasta Isparta?

Y el oficial que visa su pasaje

admite que si aún vagabundea

por infiemos de fábula, su viaje

no pudo terminar en La ódisea ${ }^{7}$.

\section{Eneas, guiado por Sibila, baja a los infiernos en busca del alma de su padre}

(...) Entonces, la profetisa comenzó a hablar así: "Caudillo esclarecido de los Teucros, (...) Encerrados aquí, aquí atienden su castigo aquellos a quienes, mientras tuvieron vida, fueron aborrecibles sus hemanos; los que a su padre hirieron o produjeron fraude a su cliente; o los que se tendieron sobre las riquezas halladas sin dar parte de ellas a los suyos -éstos son la más grande muchedumbre- y los que por adulterio fueron muertos; los que siguieron armas impías y no temieron quebrar la fe a sus señores. No pidas que te sea enseñada cuál es la pena ni la guis a y la suerte que les hundió. Unos hacen rodar un gran peñón; otros cuelgan fijos en los radios de unas ruedas; sentado está, y eternamente lo estará, el infeliz Teseo; y Flegias, el más mísero de todos, amonesta a los demás y, con gran voz, por las sombras va exhortando: ¡Aprended justicia a los avisados y a no despreciar a los dioses! Este vendió su patria por dinero y le impuso un tirano poderoso, hizo y deshizo leyes según tasa; este otro inva dió el tálamo de su hija y contrajo vedados himeneos; todos osaron concebir grandes maldades y cogieron el fruto de su osadía. No, ni que yo tuviera lenguas ciento, y bocas ciento y férrea voz, no podría expresar todas las formas de la maldad ni puntualizar todos los nombres de las penas":

Como La Odisea, La Eneida, de Virgilio, el mismo que acompañó a Dante en su viaje a los infiemos, nos cuenta la historia humana de siempre y de cualquier

\footnotetext{
${ }^{7}$ Angel Marcel. (Poema inédito).

${ }^{8}$ VIRGILIO. La Eneida" en: Obras completas de Virgilio y Horacio. Madrid: Aguilar. 1945, p. 305. 
parte: fraudes, imposturas, odios, imitaciones, parricidios, avaricias, incestos y adulterios; agresiones, traiciones y tiranías. Sólo que, a diferencia del de Homero, el infierno del poeta latino tiene un sentido más claro de cas tigo, como quiera que el reino de Hades pareciera ser tan sólo el imperio de los muertos.

No deja de llamar la atención el que Eneas hable con la sombra de los difuntos, entre ellos Palinuro, Dido y Anquises, su padre, quien le muestra las almas de los que no han nacido todavía y habrán de tejer después la historia de Roma: Silvio, hijo de Eneas y de Lavinia; Rómulo, Bruto y varios otros, hasta llegar a César, Pompeyo y Augusto, para ilustrar, quizás, la es encia adivinatoria de la poes ía que he señalado antes; ni deja de sorprender que Eneas baje a los infiemos en busca de Anquises, su progenitor, como mucho tiempo después lo hará Juan Preciado, el héroe del mexicano Juan Rulfo, cuando vaya a Comala en busca de Pedro Páramo, su padre.

\section{Dante baja a los infiernos}

Ajuicio de Borges, en su estudio preliminar de la Comedia, "no hay cosa en la tierra que no esté ahi'"

...El poema de Dante, retablo del universo, tríptico -como El jardín de las delicias, de Hieronimus Bosch, funda con rasgos precisos, con probidad y con mesura y sin el las tre de la hipérbole, los tres orbes de la muerte: el del pecado, en el infierno; el de la contricción, en el purgatorio y el de la beatitud, en el paraíso.

Bajo la égida de Virgilio, y guiado por él en su viaje por los dos primeros reinos, ingresa el florentino de patria, mas no de costumbres, a aquel mundo de rigurosa topografía, que no es otra cosa que el estado de las almas después de la muerte, bien sea que merezcan el castigo por carecer de la Gracia; la misericordia, por haber muerto arrepentidas o la gloria etema por estar llenas del Espíritu.

Tan severa como la misma topografía es el rango de faltas y valores que establece Dante en su epopeya, bien que oficie como juez o verdugo, o bien como el teólogo que condena a los pecadores, aunque como hombre -y más, como enamorado de Beatrice- los comprenda. De la mano de Dante bajemos, pues, al infierno.

Cabe el monte de Sión se abre has ta el centro de la tierra un cono invertido, que se divide en nueve círculos concéntricos que semejan las gradas de un estadio, y tasan la gravedad de las faltas según se acerquen o se alejen del vértice que ocupa el trono de Lucifer.

\footnotetext{
${ }^{9}$ BORGES, Jorge Luis. "Estudio preliminar" en: La divina comedia. Clásicos universales. San Sebastián: Txertoa. 1980, p. v.
} 
Allí están, en el primer círculo -en el limbo-, los no bautizados; que existen con un deseo sin esperanza. En el segundo, los lujuriosos giran en un torbellino sombrío; soportan los golosos una lluvia de granizo, en el tercero; en el cuarto, avarientos y despilfarradores empujan pesadas rocas; en el quinto flotan, desgarrándose, en la laguna Estigia los iracundos, y permanecen bajo sus aguas los indolentes; en el sexto, los ateos y los herejes padecen dentro de sepulcros que arden; sufren, en el séptimo, los violentos: si han agredido al prójimo, fluctúan sobre un río de sangre hirviente; si han ejercido violencia contra sí mismos, se convierten en árboles sectos; si crueles con Dios, toleran, inmóviles, una lluvia de fuego, y se han atentado contra natura, reciben, huyendo, un aguacero de llamas. En el octavo círculo, los fraudulentos pagan su castigo: los seductores corren fustigados por demonios; los aduladores se hunden en un estercolero; se quedan los simoníacos enterrados con la cabeza abajo; los magos y adivinos muestran el rostro volteado hacia la espalda; los cohechores caen en un lago de pez hirviente; andan con pesadas capas de plomo los hipócritas; los ladrones intercambian su forma con serpientes; arden dentro de llamas los malos consejeros los cismáticos sufren heridas y mutilaciones, y padecen los falsificadores toda suerte de enfermedades. Por fin, en el noveno círculo -el que señala el colmo de las culpas-, los traidores a parientes, coopartidarios, amigos y bienhechores, perduran sumidos en el hielo.

Aunque nuestro itinerario hoy excluya el paraíso en La Comedia, no huelga recordar que Dante ingresa a la Gloria de la mano de Beatrice, ahora sin la guía de Virgilio que no merece la visión de Dios por no haber recibido las aguas bautismales. Ni sobra sugerir que es el amor el que nos da la Gracia, como quiera que llena nuestras faltas y redime todas nuestras culpas, y nos permite decir de él lo que ha dicho Milan Kundera de la poesía, cuyo sentido "(...) no consiste en deslumbrarnos con una idea sorprendente, sino en hacer que un instante del ser sea inolvidable y digno de una nos talgia insoportable"10.

\section{Macondo, o el infierno de la soledad}

Gabriel García Márquez, nacido en 1928 en Aracataca, una tórrida aldea del departamento del Magdalena, en el Caribe colombiano -muy parecida a Macondo-, hijo de Gabriel Eligio García, telegrafista del pueblo natal del escritor, y de Luisa Santiaga Márquez, y nieto del coronel Nicolás Márquez Iguarán y de Tranquilina Iguarán Cotes -primos hemanos entre sí, como eran primos también José Arcadio Buendía y Ursula Iguarán, los fundadores de Macondo y de la estirpe de los Buendía-, antes que guionista de cine y narrador, y antes que reportero y periodista, ha sido un gran poeta, quiere decir, un hombre en es tado de alerta que, al despersonalizarse y al entregar su yo al mundo en amorosa relación de mutuo reflejo, ha bajado a los infiemos, a lo profundo de la realidad humana, para crear

\footnotetext{
${ }^{10}$ KUNDERA. Milan. La inmortalidad. Barcelona: Tusquets, 1987. p. 38.
} 
un estilo y un universo que trascienden el tiempo y el espacio -el aquí y el ahora- y se hace, por tanto, digno sucesor de Homero, de Virgilio y Dante.

De su abuelo, el coronel Nicolás Márquez lguarán tomó, según parece, el talante y la catadura que habrían de animar al coronel Aurealiano Buendía, personaje de algunas de sus obras; y de su abuela Tranquilina, el manejo suntuoso del idioma y el modo espontáneo de narrar que, a la manera de Kafka o de la Biblia, hacen verdadero lo increíble.

Estudiante fallido de Derecho en Bogotá y Cartagena a partir de 1947, García Márquez o Gabo, como se le conoce entre sus amigos- revela desde entonces su vocación poética. De esa época son sus primeros cuentos que habrá de recoger después en el libro Ojos de perro azul, publicado en 1974.

Aunque autor de muchas obras, como La hojarasca, su primera novela, y Relato de un náufrago, publicadas en el 55; El coronel no tiene quién le escriba, en el 57, La mala hora y Los funerales de la mamo grande, en el 62, Cien años de soledad, en el 67; La increíble y triste historia de la cándida Eréndira y de su abuela desalmada, en el 69; el libro de reportajes Cuando era feliz e indocumentado, en el 73; El otoño del patriarca y Crónicas y reportajes, en el 75; Crónica de una muerte anunciada, en el 81; El amor en los tiempos del cólera, en el 85; El general en su laberinto, en el 89; Doce cuentos peregrinos, en el 93, y Del amor y otros demonios, en abril del año pasado, Gabriel García Márquez puede considerarse creador de un solo libro, el de la soledad; y, aunque las únicas obras que ocurren en Macondo son La hojarasca, algunos de los cuentos de Los funerales de la mamo grande, y por su puesto, su novela fundamental Cien años de soledad, debo afimar que todos los lugares y ambientes de sus relatos de una u otra forma participan de la topografía y condición de aquel infierno.

Aunque Martha Canfield ${ }^{11}$, entre otros varios críticos, suscribe la opinión de que García Márquez, además de la invención de Macondo, crea un estilo poético inconfundible dentro del llamado realismo mágico, el escritor ha dicho varias veces que se niega a tal encasillamiento por sentirse más cercano del realismo. Lo que ocurre, según él, es que nuestra realidad latinoamericana excede con creces nuestras facultades imaginativas.

(...) Poetas y mendigos, músicos y profetas, guerreros y malandrines (dijo en Estocolmo al recibir el Premio Nóbel de literatura en 1982), todas las criaturas de aquella realidad desaforada, hemos tenido que pedirle muy poco a la imaginación, porque el desafío mayor para nosotros ha sido la insuficiencia de los recursos convencionales para hacer creíble nues tra vía. Este es, amigos, el nudo de nues tra soledad ${ }^{12}$.

\footnotetext{
${ }^{11}$ ANFIELD, Martha L. Gabriel Márquez. Bogotá: Procultura, 1991, p. 17.

${ }^{12}$ GARCÍA MÁRQUEZ. Gabriel. La soledad de América Latina. Discurso pronunciado en Estocolmo en la recepción del Premio Nóbel de Literatura, 1983.
} 
Sea adecuada o no, justa o injusta la clasificación de su obra dentro del movimiento del realismo magico, fórmula que propuso Uslar Pietri en 1948 para denominar las nuevas formas de expresión que se imponían en nuestra América y que habrían de alcanzar su máximo esplendor y desarrollo con los escritores del "boom" latinoamericano, lo cierto es que García Márquez refleja de modo poético los procesos y transformaciones de nuestro devenir y hace de la novela, como lo plantea Milan Kundera ${ }^{13}$, un método de indagación de las caras ocultas del ser humano, de las que ni la filosofía ni las ciencias occidentales -y menos aún el positivismo- han querido ocuparse desde la aparición de la edad moderna, en ja Europa de los siglos XV y XVI.

Nada de extraño tiene, pues, que "este colombiano errante y nostálgico" -como él mismo se define- ahonde, como querían los surrealistas, en el universo de lo mágico, en el mundo de los sueños y en los laberintos del humor, y halle finalmente la síntesis perfecta en que sujeto y objeto, fondo y forma, realidad y poema se hacen uno con él y con nosotros, como uno es el orbe en que vivimos, sólo que escindido por el absurdo divorcio entre saber y vida, sentimiento y razón, cielo e infierno, hombre y animal; vicios estos, por desgracia, tan de la esencia de las mal llamadas sociedades avanzadas.

Quiero imaginar la cara de asombro de quienes lo escucharon decir en Estocolmo:

Antonio Pigafetta, un navegante florentino que acompañé a Magallanes en el primer viaje alrededor del mundo, escribió a su paso por nuestra América meridional una crónica rigurosa que sin embargo parece una aventura de la imaginación. Contó que había visto cerdos con el ombligo en el lomo, y unos pájaros sin patas, cuyas hembras empollaban en las espaldas del macho. $Y$ otros como alcatraces sin lengua, cuyos picos parecían una cuchara. Contó que había visto en engendro animal con cabeza y orejas de mula, cuerpo de camello, patas de ciervo y relincho de caballo. Contó que al primer nativo que encontraron en la Patagonia le pusieron enfrente un espejo que aquel gigante enardecido perdió el uso de la razón por el pavor de su propia imagen ${ }^{14}$

Cualquiera diría que así como Dante, hallándose en ja mitad del camino de la vida, se ve en medio de una selva oscura y, al emprender el ascenso por la colina solitaria, logra, con la ayuda de Virgilio, eva dir la amenaza de la pantera veloz, del león rabioso y de la loba insaciable, y hacer su entrada con él a los infiemos, de igual manera, a mitad del camino de esta conferencia, me dispongo a ingresar con ustedes al infiemo de Macondo, cuya puerta pudiera estar custodiada por los engendros de que dio cuenta Pigafetta, y que no pueden ser otros que los de nuestra realidad de cada día.

\footnotetext{
${ }^{13}$ KUNDERA, Milan. El arte de la novela. Barcelona: Tusquets, 1990, p. 48.

${ }^{14}$ GARCÍA MÁRQUEZ. Gabriel. Op. cit. 
En este contexto, no repugna, pues, a nues tra mente -y menos aún al corazónque todas las aldeas marginales $y$, en general, las provincias latinoamericanas, como lo afima la ya citada Martha Canfield ${ }^{15}$, estén representadas en Macondo; que el devenir de tantas ciudades nuestras, desde el río Grande hasta la Patagonia, otrora prósperas y florecientes como Potosí, Huancavelica, lquitos o Manaos y que hoy padecen el rigor de la miseria, se miren en el espejo de Macondo; que, además, este averno al que estamos ingresando y que, a diferencia de otros infiemos, no levanta sus muros en el más allá, después de la muerte, sino en el más acá, mientras vivimos, sea a la vez terrible y bella metáfora de América Latina, desde la insularidad primitiva del edén aborigen hasta las guerras civiles y el imperialismo norteamericano, que nos lleva a caballo en el potro cerero del subdesarrollo, pasando, claro está, por la conquista y la colonia. Vida, pasión y muerte de este cris to latinoamericano que, como en La Piedad, de Miguel Angel, espera la resurrección en los brazos desolados de la madre, mucho más joven que él, en gracia de su hermosura.

Bien labrado el silen cio. La figura quiera mirarlo. El hijo no la mira.

La fragancia del mámol sólo aspira

a la amarga entidad de la escultura.

Bien talladas las manos. La hendidura

del corazón, sin ánima y sin ira;

viejas nostalgias de varón respira

un Dios con pies de estatua y de criatura.

Monumento. Metafora. Renuncia

del amor del oficio y de la vida;

memoria de la sangre y de la guerra.

No hay tal nación. No hay madre. Lo denuncia

la soledad de América domida

sobre el duro regazo de la tierra $a^{16}$.

Y, como si no fuera suficiente, tampoco repugna a nuestra mente -y menos aún al corazón- ver cómo en aquel espejo que refleja la antenora de Macondo, se escribe de derecha a izquierda el suceso y mudanza de la sociedad humana, condenada por quién sabe qué designio a nacer sin elegir ja patria ni los padres, a crecer en el dolor y el desamparo, a llegar a la cima de la yana montaña y a declinar y morir en la nostalgia, con lo que -dicho no sea de paso- se inscribe la metáfora en la esfera de lo universal y hace suyos los versos de Manrique: "Nuestras vidas son los ríos que van a dar al mar, que es morir".

\footnotetext{
${ }^{15}$ CANFIELD, Martha L. Op. cit., p. 16.

${ }^{16}$ ÁNGEL MARCEL. Op. cit., p. 72. 
En el tiempo histórico, podríamos situar el origen de Macondo en la primera mitad del siglo XIX que, a la vez, coincide con la génesis del mundo:

Macondo era entonces (se lee en la primera página de Cien años de soledad) una aldea de veinte casas de barro y caña brava construida a la orilla de un río de aguas diáfanas que se precipitaron por un lecho de piedras pulidas, blancas y enormes como huevos prehistóricos ${ }^{17}$

Mundo inoœnte y primordial, carente de muchas cosas, que no ha acabado de probar las sales del bautismo: "El mundo era tan reciente, que muchas cosas carecían de nombre, para mencionarlas había que señalarlas con el dedo"18

La insularidad de Macondo, como un infiemo tropical cercado por la selva y lejos del mar de las Antillas, prefigura el aislamiento de nuestra América latina, lejos del concierto del mundo y las naciones y en perenne lucha -sin espera y sin esperanza- por conciliar el decurso de los tiempos con su historia estancada, historia de soledad, olvido y muerte.

Macondo o nuestra América Latina, en la que José Arcadio Buendía, fundador de la estirpe, se nos aparece como un inspirado patriarca de la Biblia, con gesto y talante de conquistador español, pasa, es cierto, del estado de villorrio primitivo en la primera parte de la obra- a la condición de ciudad modema, en la segunda. No obstante, ni el ferrocarril ni el telégrafo ni el cine, ni los adelantos que trae Melquíades, ni los extranjeros norteamericanos y europeos que llegan a vivir en sus dominios, logran romper el aro de esa semiente en muda en que muerde la cola, pues esta patria que nos ha dado el nombre sin elegirla a ella, identifica su tiempo lineal, histórico, irreversible -el tiempo que va de la fundación $\mathrm{h}$ asta su declive y hundimiento- con el tiempo mítico y circular, como si fuera y-no fuera posible para nosotros, en palabras de Octavio Paz, "un caminar de río que se curva, / avanza, retrocede, da un rodeo / y llega siempre"19

¿Cuál ha sido entonces nuestro pecado como para merecer un infierno tal, digno del astuto Sísifo? Nunca ha dejado de admirarme desde mi amistad con las palabras, que el témino ladino, que significado taimado, pícaro, zorro, sagaz y cazurro, además de esclavo o africano ya apto para el trabajo en América, se derive de latino y que, por tanto, nuestra América latina lleve implícito en su nombre ese estigma de la condición humana, que nos aparta de la ingenuidad del niño que quiere para el hombre superior el Evangelio, y Federico Nietzsche, para el superhombre; astucia, picardía y sagacidad que nos han hecho insolidarios y egoístas, incapaces de amor, y cada vez más solitarios, desde la conquista y la colonia, esa empresa alucinada que trajo hasta aquí, como puede leerse en EI otoño del patriarca, "unos forasteros que parloteaban en lengua ladina pues no decían el mar sino la mar y llamaban papagayos a las guacamayas, almadías a los cayucos y azagayas a los arpones ${ }^{, 20}$; hasta la fundación de estas repúblicas, cuyos

\footnotetext{
${ }^{17}$ GARCÍA MÁRQUEZ. Gabriel. Cien años de soledad. Buenos Aires: Sudamericana, 1970. p. 9.

${ }^{18}$ Ibid

${ }^{19}$ PAZ. Octavio Piedra de sal.

${ }^{20}$ GARCÍA MÁRQUEZ, Gabriel. El otoño del patriarca. Barcelona: Pb,a y Janés. 1975. p. 44. 
líderes tan miopes, tan astutos y egoístas ellos también, no se dieron cuenta del talón de Aquiles que nos afeaba el paso y nos hacía, por tanto, fácil presa de potencias extranjeras.

Esta falta de amor en que consiste la soledad, según García Márquez, halla su expresión en el desamor del semental macondiano, antípoda del amante verdadero que, como el poeta, debe despersonalizarse y dar al otro su ser sin condiciones y sin esperar siquiera la respuesta. Como Aureliano que delira por Remedios Moscote, los machos macondianos se pierden en desvaríos pasionales y sensibleros, pero nunca se entregan de veras al amor, pues ellos son narcisos y conquistadores y ya se sabe, como reza el epígrafe de Crónica de una muerte anunciada cita de Gil Vicente que "La caza de amor es de altanería".

Sin embargo, la soledad asumida como falta de solidaridad, encuentra su cabal expresión en el incesto, "el Ilanto más antiguo de la historia del hombre ${ }^{21}$, en "los laberintos más intrincados de la sangre",22

A tono con el pensamiento de Ortega y Gasset, quien ve en el tabú el origen de la metáfora $^{23}$, pues no se puede nombrar lo que es prohibido y hay que mencionarlo, entonces, con otros nombres, Gabriel García Márquez asienta en el tabú del incesto la vasta y bella metáfora de Macondo, cuya fundación, a juicio de Ernes to Volkening -citado por Michael Palencia-Roth ${ }^{24}$, estuvo precedida por la unión incestuosa de José Arcadio Buendía y Ursula Iguarán, los primeros padres de la estirpe, y cuya peripecia circular se cierra con el incesto de Amaranta Ursula, hija de Fernanda del Carpio y de Aureliano II y tía de Aureliano Babilonia -ese adorado antropófago- a quien se entrega y de quien concibe al último Aureliano con cola de cerdo, el único de la progenie engendrado con amor.

Entre el Génesis, que da cuenta del incesto de José Arcadio Buendía y Ursula Iguarán, nuestros primeros padres, quienes temerosos de engendrar iguanas, huyen de su pueblo y fundan a Macondo, y el Apocalipsis, también precedido por el amoroso incesto entre tía y sobrino, de cuya unión nos queda la terrible maravilla de un último Aureliano con cola de cerdo, se teje en complicada urdimbre la odisea de los demás incestos, círculos todos del infierno sostenidos por el doble fundamento del imperio moral que encarna Ursula Iguarán, madre legítima de José Arcadio,.del coronel Aureliano y de Amaranta, y el dominio de Pilar Ternera, columna tierna y bovina, y madre, a la vez de la ilegitimidad, de quien descienden los demás Buendías.

Alí están: José Arcadio, el primogénito, quien desea a su propia madre cuando piensa en Pilar Temera, y después cede a la tentación de un incesto sicológico al

\footnotetext{
${ }^{21}$ GARCÍA MÁRQUEZ. Gabriel. Cien añas de soledad. Op. cit. p. 334.

Ibid.. p. 350.

${ }^{22}$ Ibid., p. 350

${ }^{23}$ ORTEGA y GASSET. José. "El tabú y la metáfora". En: La deshumanización del arte. Madrid: Revista de Occidente, 1967. p. 46.

${ }^{24}$ PALENCIA-ROTH. Michael. Gabriel García Márquez. Madrid: Gredos. 1983. p. 96. 
casarse con Rebeca Montiel, criada y educada como su hemana, aunque después nos enteramos- no lo era. El coronel Aureliano Buendía, amante -como su hermano José Arcadio- de Pilar Ternera, y quien recibe de ella en el amor un amor de madre. Años después, hombre ya maduro, establece una relación casi de padre a hija al enamorarse de Remedios Moscote, una niña de tan solo nueve anos, que llega a ser su esposa.

Arcadio y Aureliano José, por su parte, hijos de José Arcadio y del coronel Aureliano Buendía en Pilar Ternera, sienten por su madre apetitos incestuosos. Y el mismo Aureliano José se enamora de su tía Amaranta, mientras ella también lo desea.

Renata Remedios y su padre Aureliano II, tienen con frecuencia gestos y comportamientos de amantes. En fin, José Arcadio, hijo de Aureliano II y de Fernanda del Carpio, siente por Amaranta, su tía abuela ya entrada en años, tendencias incestuosas, y deviene por despecho de su amor en homosexual y excéntrico degenerado.

"Toda buena novela -ha dicho García Márquez es una adivinanza del mundo"25, vale decir, un acertijo con voz de profecía, anuncio que, a la vez, es cifra de algo oculto sobre lo que hay que proyectar la luz del intelecto, pero, sobre todo, la luz del corazón. En la opinión de Michael Palencia-Roth ${ }^{26}$ y de quienes compartimos su criterio, el enigma de la obra garcíamarquiana está en su foma circular, en gracia de la cual el último incesto de Amaranta Ursula y Aureliano Babilonia nos remite al incesto de los primeros padres, José Arcadio Buendía y Ursula Iguarán, así como el Apocalips is -la escatología-coincide con el Génesis de Macondo. Principio y fin que se encuentran, culebra en muda que se muerde la cola, tiempo lineal que se vuelve círculo como toda buena poesía, para predecir y relatar el remolino fatal de nuestras faltas que nos condenan al infierno de la soledad, a no ser que tuviéramos el privilegio de que Aureliano Babilonia acabara de descifrar los pergaminos:

Sin embargo (dicen las últimas palabras de Cien años de soledad), antes de llegar al verso final ya había comprendido que no saldría jamás de ese cuarto, pues estaba previsto que la ciudad de los espejos (o los espejismos) sería arrasada por el viento y desterrada de la memoria de los hombres en el instante en que Aureliano Babilonia acabara de descifrar los pergaminos, y que todo lo escrito en ellos era irrepetible des de siempre y para siempre, porque las estipes condenadas a cien años de soledad no tenían una segunda oportunidad sobre la tierra $^{27}$

${ }^{25}$ DURAN. Armando. "Conversaciones con Gabriel García Márquez" citado por Michael PalenciaRoth. Op. cit. p. 112.

${ }^{26}$ PALENCIA-ROTH. Michael. Op. cit., p. 113.

${ }^{27}$ GARCÍA MÁRQUEZ. G. Cien años de soledad. Buenos Aires: Sudamericana, 1970. p. 350. 
Roguemos, pues, para que Aureliano Babilonia termine de descifrar los pergaminos, que no pueden ser otra cosa que la novela misma, para que cese de girar la rueda y el destino nos libre de las siete plagas: la del insomnio y el olvido; la de las guerras civiles; la de la decadencia de la explotación del banano y de nuestros demás recursos naturales, por cuya causa nos matamos: la del diluvio; la del infiemo de la selva, ya cantado en La vorágine por José Eustasio Rivera; la del huracán que nos convierte en "un pavoroso remolino de polvo y escombros" ${ }^{28}$ y, por último, la de la desdicha de nuestra soledad.

\title{
Comala, o el infierno de la injusticia y de la fractura de los valores morales y sociales
}

¿Y qué decir ahora de Comala, esa otra forma del infierno en nuestra narrativa?

\begin{abstract}
Vine a Comala (así empieza la obra) porque me dijeron que acá vivía mi padre, un tal Pedro Páramo. Mi madre me lo dijo. Y yo le prometí que vendría a verlo en cuanto ella muriera. Le apreté sus manos en señal de que lo haría; pues ella estaba por morirse y yo en un plan de prometerlo todo. "No dejes de ir a visitarlo me recomendó-. Se llama de este modo y de este otro. Estoy segura de que le dará gusto conocerte". Entonces no pude hacer otra cosa sino decirle que así lo haría y de tanto decírselo se ¡o seguí diciendo aún después que a mis manos les costó trabajo zafarse de sus manos muertas ${ }^{29}$
\end{abstract}

Con estas sobrecogedoras palabras nos introduce Juan Rulfo al báratro de su infierno. Para este escritor mexicano, nacido en 1918, creador de El llano en llamas -un prodigioso libro de cuentos de los que acaso recordemos, entre los más bellos, a "Macario", "Es que somos muy pobres", "Diles que no me maten", "Luvina" y "No oyes ladrar los perros"- y "autor también de Pedro Páramo -una novela perfecta, ambos textos fundamentales en el ya vasto y rico concierto de nuestras letras continentales, Comala, una palabra que probablemente se derive de comal, disco de barro que se usa en México y Centroamérica para cocer las tortillas de maíz, designa en la novela de que vamos a ocupamos por breve espacio (para no ofender con el comentario la concisión del texto) un lugar de este mundo -no del otro- que se nos aparece a la vez como purgatorio, infiemo y paraíso.

De modo diferente al de Dante cuya Comedia funda un infierno de ultratumba en que destaca, a juicio de Jean Franco, "(...) la rigidez del destino de los condenados y la diversidad de los pecados castigados" ${ }^{\prime 30}$ que han privado del sumo bien a individuos específicos, el de Comala se configura como un infierno social y urbano, regido por el mestizaje y la subversión de valores, cuya consecuencia fue la escisión entre el orden moral y social del pasado en relación con el presente.

\footnotetext{
${ }^{28}$ Ibid.

29 RULFO, Juan. Pedro Páramo. Bogotá: La Oveja Negra. 1983. p. 7.

30 FRANCO. Jean. "El viaje al país de Los muertos". En: La narrativa de Juan Rulfo. Interpretaciones críticas. Antología, introducción y notas de Joseph Sommers. México: Sep/Setentas. 1974. p. 118.
} 
Como Eneas, viajero a los infiemos en busca de Anquises, Juan Preciado, cuyo nombre proviene del hebreo y significa "Yahvé es benéfico", "Yahvé es misericordioso" y es el mismo del autor del Apocalipsis, va a Comala en busca de Pedro Páramo, su padre, que es como si dijéramos que Juan el visionario, cuyo apellido significa precioso, excelente y de mucha estimación, así como jactancioso y vano, va al comal, ese disco de barro en que se cuecen las tortillas de maíz, base de la alimentación y economía precolombinas en aquella región del mundo, a buscar a Pedro Páramo, que no es otra cosa que una piedra helada.

En plan de exigencia y no de súplica, Juan Preciado va -¿o viene? al mundo del más acá, purgatorio, infierno y paraíso, "la mera boca del infierno", corno se lee en la obra, "una llanura verde", "(...) tierra de miel y de leche", "un horizonte "gris" en que todo parecía estar como en espera de algo", "blanqueando la tierra iluminándola, durante la noche", para dar cumplimiento a la última voluntad de su difunta madre: -No vayas a pedirle nada. Exígele lo nuestro. Lo que estuvo obligado a dame y nunca me dio... El olvido en que nos tuvo, mi hijo, cóbraselo caro $^{31}$

Pero este piadoso Eneas de México y, ¿por que no? también de Latinoamérica, se encuentra con que el lugar, vacío y abandonado, que debieran habitar los vivos, está ocupado por las sobras de los muertos:

Las ventanas de las casas abiertas al cielo, dejando asomar las varas correosas de la yerba. Bardas descarapeladas que enseñaban sus adobes revenidos ${ }^{32}$

Y, como en Cien años de soledad, se encuentra con que una pareja desnuda de amadores, que son hemano y hermana, y cuya casa tiene, como las demás, el techo lleno de agujeros, se hunden en una relación estéril, pues en vez de procrear, él sólo quiere el sueño, mientras a ella la desvela el más profundo remordimiento. Metáfora, sin duda, del abismo esencial entre nuestros valores morales del pasado y nuestro comportamiento del presente. Fractura, escisión como la del techo roto.

Yo le quise decir (dice ella. refiriéndole a Juan Preciado la explicación que trataba de darle al obispo) que la vida nos había juntado, acomodándonos y puesto uno junto al otro. Estábamos tan solos aquí que los únicos éramos nosotros. $Y$ de algún modo había que poblar el pueblo ${ }^{33}$.

También se encuentra Juan Preciado con otra escisión inapelable: la que afecta a los propios sentidos, pues mientras sus oídas perciben el paraíso perdido, descrito como nostalgia en la voz de su madre, lo que sus ojos ven es el infiemo de Comala, esa aldea en ruinas por culpa de Pedro Páramo, señor feudal, amo y dueño de la tribu, terrateniente obsoleto de la Media luna, cuyo hijo Juan Preciado ni siquiera merece el deshonroso legado de su apellido, como sí recibimos nosotros la deshonrosa herencia de la picaresca española que, aún hoy, en la

${ }_{31}^{31}$ RULFO, Juan. Op. Cit., p.7

32 Ibid., p. 54. (Tercera edición del Fondo de Cultura Eønómica. 1961).

${ }^{33}$ Ibid., p. 29 
antesala del siglo $X X \mathrm{X}$, nos sigue haciendo tan ladinos e insolidarios, casi que extranjeros en nuestros propios países, cuyas puertas permanecen cerradas al verdadero amor yal reconocimiento del otro.

¿Cómo salir de estos infiernos? ¿Cómo hacer cierta la quimera del amor y la utopía de la solidaridad? La solución -si es que hay alguna- no está por cierto en las manos de los poetas, pues sólo compete a ellos el oficio divino de la adivinación y el mostrar cómo hombres de carne y hueso que deciden vivir cada instante de su vida en forma por demás extraordinaria, quiero decir, del modo más poético y humano, aunque jamás escriban versos, proponen no sólo una estética para hacer más tolerable -y hasta más bella-es la tragedia de sabernos y sentirnos hombres, sino también una ética, rectora de nuestros actos, unión de nuestras fracturas, medio para entregar el ser en favor del otro; ética que consiste en desconfiar del dogma y de las verdades absolutas y en regimos por el derecho que tienen los demás a ser distintos de nosotros; ética y estética que, finalmente, nos permiten a ustedes y a mí, en Colombia, en Macondo o en Comala y, por supues to, en esta hermosa nación brasilera, que ya me va pareciendo un paraíso, elevar nuestra voz al poderoso Hades para decir esta plegaria:

Dios te salve, María, Gratia plena, el Señor es contigo, Benedicta; entre todas las víctimas, invicta, patrona del destierro y de la pena.

Ave María, compasiva helena -en la acepción más alta y más estricta-, sea bendito el fruto, la vindicta que floreció en tu vientre, Nazarena.

Sancta María, madre Celestina, que, al sesgo de tu carne cristalina, alumb raste el vía crucis de Belén,

Ora pro nobis, Venus redentora, ruega por nuestras vértebras ahora y en la hora de nuestra muerte. Amén.

padre nuestro, que estabas en el cielo y hoy estás en nosotros, pecadores. Santo sea tu nombre. Tus rencores te hacen más Dios y prójimo del suelo.

Venga a nos el tu reino paralelo a aquel de las tinieblas exteriores.

Tu voluntad no hagamos, que las flores 
en ellas mismas tienen su modelo.

Danos, Señor, el hambre cada día y la necesidad que no tenemos.

Perdónanos que no te perdonemos.

No nos dejes caer en la alegría.

Y líbranos, Señor, de la odisea

de tanta eternidad. Y que así sea.

\section{BIBLIOGRAFIA}

ÁNGEL MARCEL. Transgresión y anacronismo. Bogotá: Gimnasio Moderno, 1990.

CANFIELD, Martha L. Gabriel García Márquez. Bogotá: Procultura, 991.

DANTE Alighieri. La Divina comedia. Clásicos universales. Estudio preliminar de Jorge Luis Borges. San Sebastián: Txertoa, 1980.

FRANCO, Jean. "El viaje al país de los muertos". En: La narrativa de Juan Rulfo. Interpretaciones críticas. Antología, introducción y notas de Joseph Sommers. México:

Sep/Setentas, 1974.

GARCÍA MÁRQUEZ, Gabriel. Cien años de soledad. Buenos Aires: Sudamericana, 1970.

El otoño del patriarca. Barcelona: Plaza y Janés, 1975.

La soledad de América Latina (Dis curso de Estocolmo), 1983.

HOMERO. La Odisea. Obras maestras. Barcelona: Iberia, 1952.

KUNDERA, Milan. El arte de la novela. Barcelona: Tus Quets, 1987.

La inmortalidad. Barcelona: Tus Quets. 1990.

ORTEGA Y GASSET, José. La deshumanización del arte. Madrid: Revista de Occidente, 1967.

PALENCIA-ROTH, Michael. Gabriel García Márquez. Madrid: Gredos, 1983.

PELLEGRINI, Aldo. "La universalidad de lo poético". En: Para contribuir a la confusión general. Nueva visión, 1965. 
RULFO, Juan. Pedro Páramo. Bogotá: La oveja negra, 1983.

SAINZ DE ROBLES, Federico Carlos. Ensayo de un diccionario español de sinónimos y antónimos. Madrid: Aguilar, 1973.

VIRGILIO. 'La eneida ". En: Obras completas de Virgilio y Horacio. Madrid: Aguilar, 1945. 